\title{
Double Sequential Ballooning (Eggshell) Method for Treatment of Severe Metastatic Compression Fractures with Extra-Compartment Involvement: In Comparison with Conventional Balloon Kyphoplasty
}

\author{
Jong Seok Lee, Ho Shin Gwak², Sang-Hyun Lee ${ }^{3}$, Jungnam Joo ${ }^{4}$, Ji-Woong Kwon², Heon Yoo ${ }^{2}$, \\ Sang-Hoon Shin ${ }^{2}$ \\ ${ }^{1}$ Department of Neurosurgery, Seoul National University College of Medicine, Seoul, \\ ${ }^{2}$ Neuro-Oncology Clinic, Research Institute and Hospital, National Cancer Center, Goyang, \\ ${ }^{3}$ Department of Radiology, Research Institute and Hospital, National Cancer Center, Goyang, \\ ${ }^{4}$ Biometric Research Branch, Research Institute and Hospital, National Cancer Center, Goyang, Republic of Korea
}

Corresponding author: Sang-Hoon Shin Neuro-Oncology Clinic, National Cancer Center, 323 Ilsan-ro, Ilsandong-gu, Goyang 10408, Republic of Korea

Tel: +82-31-920-1245

Fax: +82-31-920-2798

E-mail: nsshin@ncc.re.kr

Received: August 3, 2018 Revised: August 21, 2018 Accepted: August 23, 2018

\begin{abstract}
Objective: Severely compressed vertebral fractures with extra-compartment involvement are considered relative contraindications for percutaneous vertebroplasty (PVP) and balloon kyphoplasty (BKP) in the fear of cement leakage or failure in vertebral height restoration. The purpose of the current study was to evaluate the effectiveness of a new technique known as double sequential ballooning (eggshell) method for severe metastatic compression fractures (MCFs) with extra-compartment involvement. Methods: We retrospectively reviewed 118 patients with MCF who underwent BKP between March 2002 and September 2017. Among them, 9 patients underwent BKP using the eggshell method. We analyzed the differences of radiological and clinical results between these 2 patients groups. Results: Patients who underwent BKP using the eggshell method showed a higher frequency of severe compression $(p=0.026)$, and more columns involvement as per 6 -column classification $(p=0.004)$ compared with those who underwent conventional BKP. They also showed higher frequency of paravertebral (PV) extension and PV and epidural involvement $(p<0.001)$. The median amount of injected cement was significantly higher in eggshell group compared with conventional BKP (7.5 cc vs. 6 cc; $p=0.049)$, and so, vertebral body (VB) height gain was (4 mm [range. $2-9 \mathrm{~mm}$ ] vs. $2.5 \mathrm{~mm}$ [range, $0-10 \mathrm{~mm}$; $\mathrm{p}=0.021$ ). Patients in the eggshell group showed a lower rate of cement leakage, but the difference was statistically insignificant $(p=0.273)$. Conclusion: The eggshell method enabled injection of cement and restoration of vertebral height in patients with severe MCFs with extra-compartment involvement in comparison with conventional BKP. It is expected to reduce cement leakage in these patients.
\end{abstract}

Key Words: Fractures, compression; Kyphoplasty; Spinal fractures; Spine

\section{INTRODUCTION}

Vertebral body (VB) compression fractures of variable etiology lead to back pain, decreased mobility, kyphoscoliosis, and neurological complications in patients ${ }^{36)}$. Treatment is predominantly non-surgical except in patients with neurological injury or disabling pain. Percutaneous vertebroplasty (PVP) and balloon kyphoplasty (BKP) have emerged as important surgical options in treatment of vertebral compression fractures ${ }^{28)}$. PVP and BKP are minimally invasive techniques for treating painful osteoporotic compression fractures (OCFs) vertebral malignancy, and painful hemangiomas. The goal of these treatments is to provide immediate relief from chronic pain and bone strengthening in painful $\mathrm{VB}$ compression fractures for rapid rehabilitation $^{5,9,28,35)}$. However, these procedures are generally not advised in severe VB collapse, where the VB height is reduced by more than $70 \%$ of its original height ${ }^{24)}$. Due to technical difficulties of vertebral height restoration and relatively greater complications of cement leakage, severe VB fracture or collapse has been considered an exclusion criterion ${ }^{39)}$, an unfavorable situation $^{4)}$, or a relative contraindication ${ }^{29)}$ for vertebroplastic treatment

Severe compression of the VB hinders introduction of a suitable cannula, and ballooning can lead to cortical bone fracture or end plate disruption. Nevertheless, some studies 
have attempted to challenge this contraindication for vertebroplasty in cases of severe VB collapse with no increase in complication rate re, $^{2,22,31,33)}$. Some studies suggested that using high-viscosity bone cement ${ }^{18)}$ or other equipment like sideopening injection cannulas ${ }^{26)}$ could prevent cement leakage. Others introduced modified techniques of cement injection in patients with vertebra plana ${ }^{17,18)}$. We also performed a modified technique of cement injection called eggshell method in patients with severe metastatic compression fractures (MCFs).

The purpose of the current study was to evaluate a new technique known as double sequential ballooning (eggshell) method for preventing cortical bone destruction and endplate violation during balloon inflation in BKP in cases of severe MCF with extra-compartment involvement. We analyzed clinical features and results in patients after surgical treatment using the eggshell method and compared them with those using conventional BKP.

\section{MATERIALS AND METHODS}

\section{Eligibility Criteria}

From March 2002 to September 2017, 126 cancer patients with MCF underwent BKP. BKP was performed in patients with intractable pain caused by a pathologic fracture and no evidence of neurological deficit due to epidural (ED) compression. We excluded patients with previous spinal surgeries in involved segments, OCF, infectious conditions, or compression fractures of the spine in which the primary cancer was hematopoietic such as multiple myeloma and leukemia, which tend to show a similar nature and distribution of marrow involvement (predominantly anterior and middle columns of vertebrae) as OCF does. Unlike OCF, it was expected to present cement leakage with limited restoration of $\mathrm{VB}$ height in times of routine cementoplasty in severe MCF with paravertebral (PV) extension. Therefore, in some of these patients who had severe MCFs with extra-compartment involvement, we performed a special procedure known as double sequential ballooning (eggshell method). We expected eggshell method to reduce the cement leakage, which was prone to occur by performing conventional BKP. Consequently, a total of 118 patients were found eligible and they had all undergone BKP for painful thoracolumbar MCF without neurological deficit. Among them, 9 patients underwent the double sequential ballooning (eggshell) procedure on surgeon's choice.

\section{Double Sequential Ballooning (eggshell) Method}

The eggshell method was firstly described by Greene et al. ${ }^{17)}$ in 2007 to prevent cement extravasation through the cortical bone defects during kyphoplasty. Especially for a patient with severe compression fractures, cortical bone defects could be noted during balloon inflation. Rather than aborting the procedure, the new technique was used to manage the patient's fracture by covering the defect with a small amount of cement. With this technique, balloon inflation is preceded by the injection of a small amount of cement.

Briefly, the procedure was under fluoroscopy after adminis-
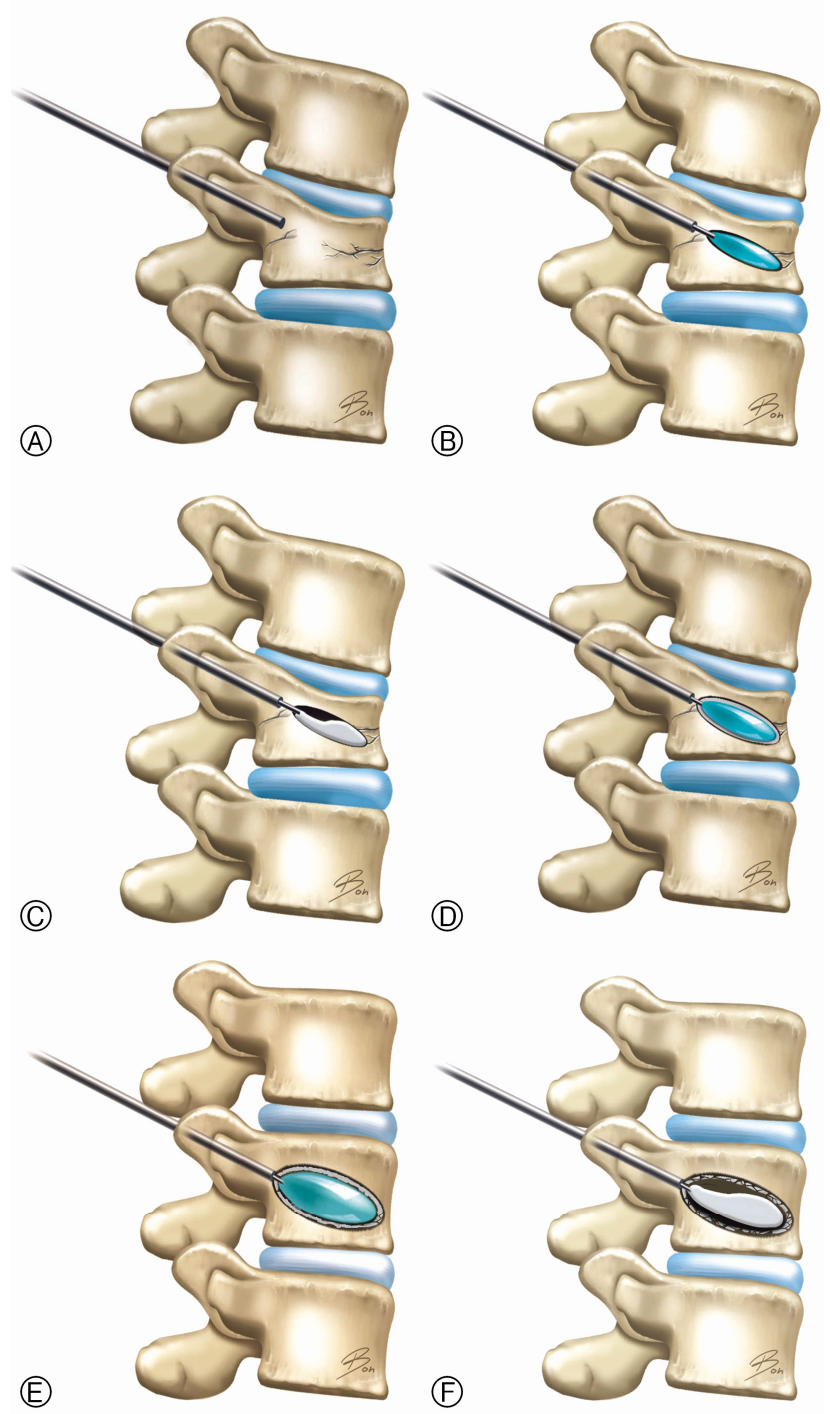

Fig. 1. Procedure of the double sequential ballooning (eggshell) method. (A) Working cannulas and inflatable bone tamps (IBTs) are inserted to target points between the endplates of severely collapsed vertebra. (B) The balloon is slowly inflated till the volume of each IBT reaches $1 \mathrm{~mL}$. (C) A small amount of polymethyl methacrylate (PMMA) is injected into the space. (D) IBTs are reinserted and slowly inflated to press PMMA against both endplates causing it to assume an eggshell shape. (E) Once the cement hardens, inflation is continued to more than $1 \mathrm{~mL}$. Inflation is continued to a maximal pressure of 200 psi or until maximal size-dependent balloon volume is reached. (F) Additional PMMA is injected into the inflated space in the conventional manner with continuous lateral fluoroscopic monitoring. 
tration of local anesthetics in the operating room, as in conventional BKP. Using a bilateral transpedicular approach, working cannulas and inflatable bone tamps (IBTs) were inserted to target points between the endplates of severely collapsed vertebrae seen on the lateral radiograph, as in conventional BKP (Fig. 1A). The balloon was slowly inflated till the volume of each IBT reached $1 \mathrm{~mL}$ (Fig. 1B). When the balloon was removed, a small amount $(1 \mathrm{~mL})$ of polymethyl methacrylate (PMMA) was injected into the space (Fig. 1C). IBTs were reinserted and slowly inflated to press the PMMA against both endplates causing the PMMA to assume an eggshell shape (Fig. 1D). Once the cement hardened, inflation was continued to more than $1 \mathrm{~mL}$. The eggshell-shaped PMMA separated and protected each endplate. Inflation was continued to a maximal pressure of 200 psi or when the maximal size-dependent balloon volume was reached (Fig. 1E). Additional PMMA was injected into the inflated space in the conventional manner with continuous lateral fluoroscopic monitoring (Fig. 1F). The previously injected eggshell-shaped cement prevented cortical bone destruction and endplate violation during balloon inflation in cases of severely collapsed VB.

\section{Clinical and Radiological Variables}

We reviewed medical records to assess age, gender, radiation therapy to involved spinal segments, preoperative visual analogue scale (VAS) scores, and pain character (with or without radicular pain). We also reviewed preoperative images to evaluate metastases to visceral organs and/or to non-spinal bones, multiplicity of spinal metastases (single vs. multiple), degree of compression (DOC; $<50 \%$ vs. $\geq 50 \%$ ), treated segments (thoracic vs. lumbar), involved lesions using 3-column theory (with or without posterior column), extent of 6-column involvement ( $<4$ vs. $\geq 4$ ), extra-compartmental involvement in tumors (none, $\mathrm{ED}, \mathrm{PV}$, or $\mathrm{ED}+\mathrm{PV})$.

Existence of visceral organ and/or bone metastases was evaluated based on preoperative imaging studies including positron-emission tomography and abdominal or chest computed tomography scans performed within three months of the surgery. Preoperative images were analyzed to assess number of spinal segments involved in metastases, treated spinal level (thoracic vs. lumbar), and DOC (percentage height of the involved level relative to average height of the upper and inferior level on sagittal magnetic resonance imaging [MRI] or lateral $\mathrm{X}$-ray). We evaluated axial extension of the lesion based on 3-column involvement at the most affected level ${ }^{37)}$, number of 6-column involvements (because the 3-columns are divided into right and left components) ${ }^{35)}$, and PV extension of the metastatic lesion ${ }^{36}$ on axial MRI. If a patient underwent BKP for multiple levels in a single procedure, we measured the variables at the most compressed segments.

We also measured postoperative DOC, postoperative VAS scores, injected cement volume, existence of cement leakage, and VB height gain after the procedure as treatment-related variables that could affect outcome.

\section{Measurement of Outcomes}

Pain improvement was assessed using the difference between pre- and postoperative VAS score which ranges from 0 indicating no pain, to 10 indicating the greatest imaginable pain. Postoperative VAS score was measured at the time of discharge (the following day after surgery) or during the first outpatient visit (1 week after discharge).

Injected cement volume and existence of cement leakage were found from medical records and imaging studies. If there were no medical records, we used the ellipsoid method for measuring injected cement volume using postoperative anteroposterior and lateral X-ray images. We measured VB height gain after the procedure using pre- and postoperative lateral X-ray images. X-ray images were reviewed by the department of radiology.

\section{Statistical Methods}

The distribution of categorical variables was summarized as count and proportion. The median and range were used for the continuous variables. Differences in categorical variables were analyzed using Fisher's exact-test due to the small sample size. Continuous variables were analyzed using Welch's $t$-test, or the non-parametric Wilcoxon rank-sum test as appropriate. A p-value $<0.05$ was considered statistically significant. For patients who underwent multiple BKP procedures, the most severely injured segment was analyzed.

\section{RESULTS}

\section{Pre-treatment Clinical and Radiological Features}

Dichotomized distributions of patient characteristics are summarized in Table 1. Among the 118 patients eligible for this study, 70 were women and 48 were men; their median age was 62.5 years (range, 27-86). Eighty-two patients (69.5\%) had only axial spinal pain, which was aggravated by sitting or standing. The remaining 36 patients (30.5\%) had additional radiating pain at the affected dermatome. The median preoperative VAS score was 5.

Spinal metastases were the only metastatic tumors in 37 patients $(31.4 \%)$. The remaining $68.6 \%$ of patients $(n=81)$ had other organ metastases. One hundred-four patients (88.1\%) presented with multiple level spinal metastases, while whereas only 14 patients (11.9\%) had a single level spinal metastasis. Treatment locations were distributed almost evenly between the thoracic $(n=60)$ and lumbar spine $(n=58)$.

Approximately one-third of patients $(n=37)$ showed severe compression fractures $(\geq 50 \%)$ based on DOC. Forty-three pati- 
ents (36.4\%) showed 3-column involvement as per the 3-column theory and 64 patients (54.2\%) showed involvement of more than 4-columns as per the 6-column classification. Patients who underwent BKP using the eggshell method showed a higher frequency of severe compression $(\mathrm{p}=0.026)$, and more column involvement as per 6-column classification ( $\mathrm{p}=0.004)$ compared with those who underwent conventional BKP. Similarly, patients in the eggshell group also showed higher frequency of PV extension $(\mathrm{p}<0.001)$, and PV and ED involvement $(\mathrm{p}=0.002)$.
These are expected results, as the eggshell method was applied in selected patients, who showed severe metastatic compression with extra-compartmental involvement.

\section{Post-treatment Clinical and Radiological Features}

As shown in Tables 1 and 2, preoperative VAS score were ranged from 5 to 3 in both groups. Postoperative VAS scores were improved median 3 (range, 1-6) in eggshell group and

Table 1. Pretreatment clinical and radiological characteristics of metastatic compression fracture patients based on intervention methods

\begin{tabular}{|c|c|c|c|c|}
\hline & Total $(n=118)$ & Eggshell $(n=9)$ & $\operatorname{BKP}(n=109)$ & p-value \\
\hline Mean age (range) & $62.5(27-86)$ & $62(52-73)$ & $63(27-86)$ & 0.757 \\
\hline Gender & & & & 0.010 \\
\hline Male & $48(40.7)$ & $0(0.0)$ & $48(44.0)$ & \\
\hline Female & $70(59.3)$ & $9(100.0)$ & $61(56.0)$ & \\
\hline Visceral metastasis & & & & 0.137 \\
\hline No & $37(31.4)$ & $5(55.6)$ & $32(29.4)$ & \\
\hline Yes & $81(68.6)$ & $4(44.4)$ & $77(70.6)$ & \\
\hline No. of spinal metastases & & & & 0.597 \\
\hline Single & 14 (11.9) & $0(0.0)$ & $14(12.8)$ & \\
\hline Multiple & $104(88.1)$ & $9(100.0)$ & 95 (87.2) & \\
\hline Treated segment & & & & 0.318 \\
\hline Thoracic & $60(50.8)$ & $3(33.3)$ & $57(52.3)$ & \\
\hline Lumbar & $58(49.2)$ & $6(66.7)$ & $52(47.7)$ & \\
\hline Degree of compression & & & & 0.026 \\
\hline$<50 \%$ & $81(68.6)$ & $3(33.3)$ & $78(71.6)$ & \\
\hline$\geq 50 \%$ & $37(31.4)$ & $6(66.7)$ & $31(28.4)$ & \\
\hline Three columns involvement & & & & 0.071 \\
\hline Anterior/Middle & $75(63.6)$ & $3(33.3)$ & $72(66.1)$ & \\
\hline Total & $43(36.4)$ & $6(66.7)$ & $37(33.9)$ & \\
\hline No. of 6 columns involvement & & & & 0.004 \\
\hline$<4$ & $54(45.8)$ & $0(0.0)$ & $54(49.5)$ & \\
\hline$\geq 4$ & $64(54.2)$ & $9(100.0)$ & $55(50.5)$ & \\
\hline \multicolumn{5}{|l|}{ Extra-compartment involvement } \\
\hline None & 51 (43.2) & $0(0.0)$ & $51(46.8)$ & \\
\hline ED & $32(27.1)$ & $1(11.1)$ & $31(28.4)$ & 0.289 \\
\hline PV & $21(17.8)$ & $4(44.4)$ & $17(15.6)$ & $<0.001$ \\
\hline$E D+P V$ & $14(11.9)$ & $4(44.4)$ & $10(9.2)$ & 0.002 \\
\hline Local radiation therapy & & & & 0.283 \\
\hline No & $43(36.4)$ & $5(55.6)$ & 38 (34.9) & \\
\hline Yes & $75(63.6)$ & $4(44.4)$ & $71(65.1)$ & \\
\hline Pain character & & & & 1.000 \\
\hline Axial only & $82(69.5)$ & $6(66.7)$ & $76(69.7)$ & \\
\hline Radiculopathy \pm axial pain & $36(30.5)$ & $3(33.3)$ & 33 (30.3) & \\
\hline Preoperative VAS & $5(0-10)$ & $5(4-8)$ & $5(0-10)$ & 0.535 \\
\hline
\end{tabular}

ED: epidural; PV: paravertebral; VAS: Visual Analogue Scale; BKP: balloon kyphoplasty.

The data is presented as number (\%) or mean (range). 
Table 2. Posttreatment clinical and radiological characteristics of metastatic compression fracture patients based on intervention methods

\begin{tabular}{lcccc}
\hline \hline & Total $(\mathrm{n}=118)$ & Eggshell $(\mathrm{n}=9)$ & $\mathrm{BKP}(\mathrm{n}=109)$ & $\mathrm{p}$-value \\
\hline Cement amount & $6(1-12)$ & $7.5(3.5-11.5)$ & $6(1-12)$ & 0.049 \\
Cement leakage & & & & \\
$\quad$ No & $82(69.5)$ & $8(88.9)$ & $74(67.9)$ & 0.273 \\
Yes & $36(30.5)$ & $1(11.1)$ & $35(32.1)$ & \\
VB height gain & $3(0-10)$ & $4(2-9)$ & $2.5(0-10)$ & 0.021 \\
Postoperative VAS & $3(0-10)$ & $3(0-4)$ & $3(0-10)$ & 0.491 \\
\hline
\end{tabular}

VB: vertebral body; VAS: Visual Analogue Scale; BKP: balloon kyphoplasty.

The data is presented as number (\%) or mean (range).

median 2 (range, 3-8) in the conventional BKP group, and the difference failed to reach statistical difference $(\mathrm{p}=0.091)$. The median amount of injected cement was significantly higher in the eggshell group $(7.5 \mathrm{~mL}$ vs. $6 \mathrm{~mL} ; \mathrm{p}=0.049)$. VB height gain was $4 \mathrm{~mm}$ using the eggshell method, and $2.5 \mathrm{~mm}$ using conventional BKP. VB height gain was also significantly higher in the eggshell group $(\mathrm{p}=0.021)$ than in the conventional BKP group. Cement leakage was found in approximately one-third of the patients $(n=36)$ of whom only 1 patient underwent the eggshell procedure. Patients in the eggshell group showed a lower rate of cement leakage $(1 / 9,11 \%)$ than those in the conventional BKP group (35/109, 32\%), but the difference was statistically insignificant ( $\mathrm{p}=0.273$, Wilcoxon rank sum test).

\section{Illustrative Case}

A 68-year-old woman presented with recalcitrant mid-thoracic back pain radiating anteriorly and decreased ambulation due to a newly progressed T8 compression fracture. Previously, she had undergone vertebroplasty for T6 and T7 pathologic compression fractures; she had also been diagnosed with lung cancer. MRI and lateral radiography showed a severe compression fracture ( $T 8 \mathrm{VB}$ height $=6.9 \mathrm{~mm}$ ) with a diffuse infiltrative enhancing lesion (Fig. 2A, B).

A decision was made to perform the double sequential ballooning (eggshell) procedure for pain control and vertebral height restoration. IBTs were placed at target points between the severely collapsed endplates of the $78 \mathrm{VB}$ (Fig. 2C). Inflation was performed until each IBT volume reached $1 \mathrm{~mL}$, and $1 \mathrm{~mL}$ of PMMA was then injected (Fig. 2D). When the cement reached the hardened phase, inflation was performed again (Fig. 2E). An eggshell-shaped PMMA cavity was seen on anterior-posterior and lateral radiography (Fig. 2F, G). Filling using PMMA was performed (Fig. 2H). Postoperative vertebral height was $15.4 \mathrm{~mm}$ (Fig. 2I) and the height gain was $8.5 \mathrm{~mm}$. The patient sustained no complications and her radiculopathic pain was dramatically eliminated without analgesics.

\section{DISCUSSION}

Since the introduction of PVP for treating vertebral heman- gioma in $1987^{13)}$, it has become a predominant treatment option in the management of axial back pain caused by vertebral compression fractures of various etiologies. PVP has not been able to restore lost vertebral height or correct the resultant kypho$\mathrm{sis}^{8,15,27)}$. Consequently, the patient's center of gravity could be shifted anteriorly, thereby producing longer flexion moment on the apex of the kyphotic deformity. Because of this resultant force, vertebroplasty has the potential for aggravating existing deformities or creating additional fractures.

In the early 1990s, a modified vertebroplastic procedure known as BKP was introduced to restore lost vertebral height or to correct kyphotic deformities ${ }^{27)}$. This procedure involved use of inflatable balloons to elevate end plates, reduce the fracture, and create a cavity for maximal cement volume. This minimally invasive procedure has been shown to provide immediate pain relief and restore vertebral integrity and stability ${ }^{1,11)}$. It restored VB height, improved kyphosis, increased strength of the VB, and restored stiffness. Low-pressure injection of cement into the cavity in the VB could also significantly lower extravertebral leakage ${ }^{20)}$.

Vertebrae augmented with PMMA are stiffer than fractured vertebrae, decreasing the ultimate load to adjacent vertebrae by $8 \%$ to $30 \% \%^{3)}$. Studies have reported subsequent vertebral fractures occurring at rates of $3 \%$ to $29 \%$ after $\mathrm{BKP}^{14,21,23)}$, and $12 \%$ to $52 \%$ after $\mathrm{PVP}^{16,37)}$. Controversy still exists as to whether new VB fractures are simply a result of natural progression of disease or whether they are consequences of augmentation. Leakage of PMMA into the disc space is cited as an important risk factor for subsequent vertebral fractures ${ }^{6,13)}$.

Previous reports have identified fractures with retropulsion of fragments within the neural foramen, local infection, coagulation disorders, and spread of tumors within the ED space and vertebral plana as contraindications for PVP and $\mathrm{BKP}^{11,12)}$. When osteonecrosis and pseudoarthrosis are evident along with vertebra plana ${ }^{9,30)}$ vertebroplasty has been considered more suitable ${ }^{7}$.

In vertebra plana, severe compression of the VB complicates introduction of a suitable cannula at the vertebral level. Additionally, ballooning can lead to cortical bone fracture or end plate disruption. A few reports have claimed that vertebra plana was nonresponsive to BKP or that BKP was less effective at relieving 

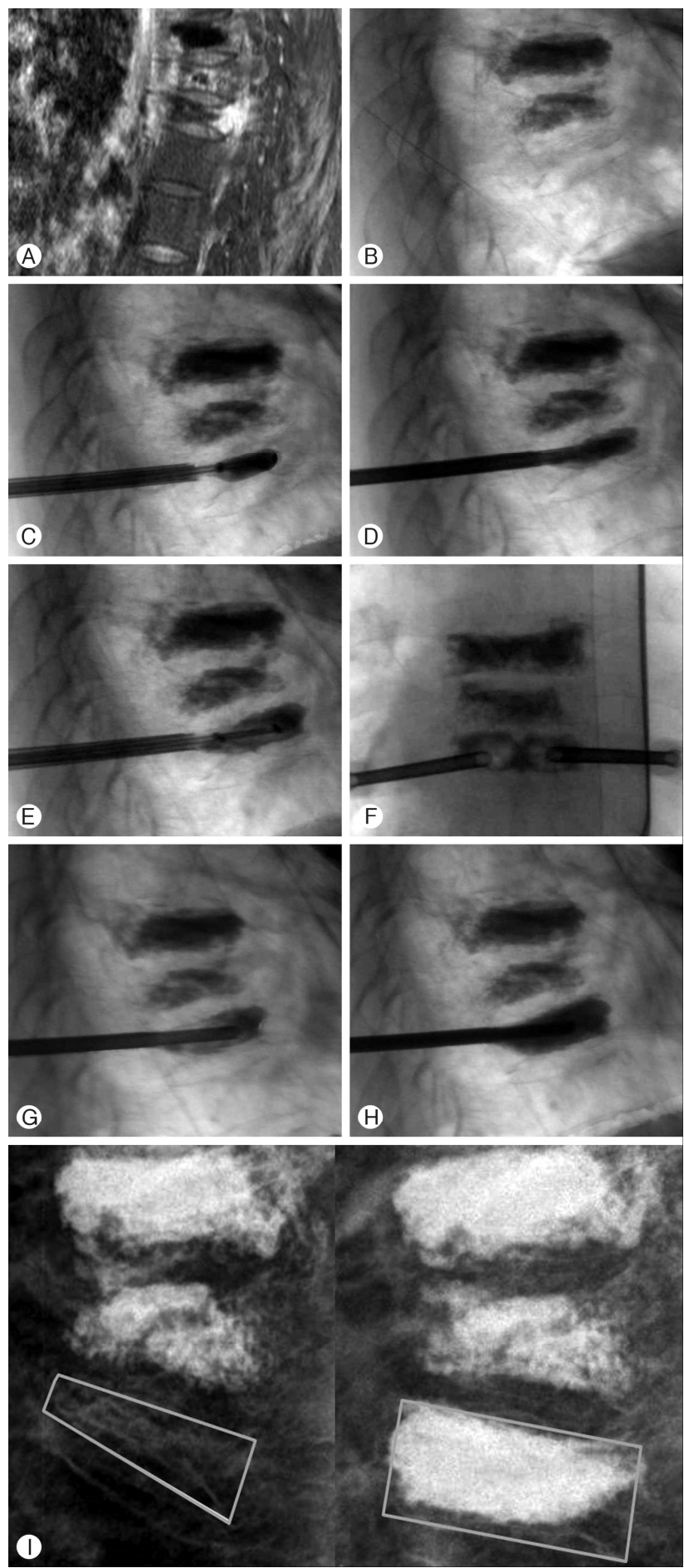

Fig. 2. A 68-year-old patient with vertebra plana undergoing balloon kyphoplasty using the eggshell method. (A) Sagittal enhanced T1-wieighted magnetic resonance image demonstrating severe compression fracture (T8 vertebral body height $=6.9 \mathrm{~mm}$ ) with a diffuse infiltrative enhancing lesion. (B-H) Lateral fluoroscopic images demonstrating the method of double sequential ballooning (eggshell). (I) Lateral radiographs before and after treatment revealing $8.5 \mathrm{~mm}$ height gain (preoperative vertebral height $=6.9 \mathrm{~mm}$, postoperative vertebral height $=$ $15.4 \mathrm{~mm})$. pain in vertebra plana than typically reported for $\mathrm{PVP}^{25,31)}$.

In contrast, our study showed suggestive positive results in patients with vertebra plana who were considered to experience no benefit with conventional BKP. We performed the eggshell procedure in patients with severe MCF and multiple column involvement. Although VB injury was more severe in patients who underwent the eggshell procedure compared with those who underwent conventional BKP, we were able to inject more cement in them and restore more of their VB height. These results could be interpreted as affected by the fact that eggshell method was performed in severely compressed patients, who had potentially higher room for both cement injection and height restoration. However, there was no evidence that more severe compression fracture was related to more VB height restoration or cement injection when performing conventional BKP in previous literature. Rather, high fracture severity grade was a risk factor for complication in cementoplasty ${ }^{10)}$.

In addition, cement leakage in the eggshell group was apparently low although it did not reach the statistical significance. As has been reported, leakage rate after BKP may be $4.8 \%$ to $39 \%^{10,19,28,32,34,38)}$. In our study, cement leakage rate was $11 \%$ in the eggshell group and 32\% in the conventional BKP group. The eggshell method makes $1 \mathrm{~mL}$ primary shells in cancellous vertebrae and enables greater restoration of destructed vertebral height by inflation and fracture of primary shells. The primary shell provides alternative force to restore height in the cancellous bone with destructed cortical bone and endplates. Therefore, we suggest that the double sequential ballooning procedure will help expand indications for cement injection in patients with severe VB compression fractures at lower complication rates.

The major limitation of our study is that the number of patient in eggshell group is relatively small compared with the conventional BKP group. It is because that new technique is limited to perform in patients in current Korean insurance system, which does not cover BKP in severe (>70\%) compression fracture. Thus, there would less power in statistical significance because of imbalanced sample size. We tried to overcome this problem by non-parametric analysis of Wilcoxon rank sum test. We also had tried to analyze the result by matched analysis, but it was impossible due to sample size, which was still short to be individually matched in several variables. As an alternative analysis, we performed subgroup analysis by excluding patients BKP group having biased variables such as number of spinal metastases, less than $4 / 6$ columns involvement and extra-compartment involvement (data not provided), but failed to find variable that define beneficial group from eggshell method. In this study, more amounts of cement injection and VB height gain was found in eggshell group. However, we regret that statistical power of the analyses was weak due to small number of patients. Therefore, further study with more sample size of eggshell method will be needed to validate the technique to be effective in severe MCF with extra-compartment involvement. 
A major limitation of this study was that it was a retrospective analysis of small number of patients with cancer metastases undergoing vertebral procedures. Furthermore, the number of patients who underwent the eggshell procedure was very small due to limited coverage of eggshell method in current Korean insurance system as described in Discussion. Exact indications for the eggshell procedure have not been defined yet. Thus, further study is still required for detailed indication of the eggshell method with prospective protocol describing exact radiological and clinical variables.

\section{CONCLUSION}

Using the double sequential ballooning (eggshell) method, we performed a modified BKP procedure in patients with vertebra plana, which has been considered as relative contraindication for cement injection. We were able to inject more cement and cause greater VB height restoration in patients with severe MCFs with extra-compartment involvement, which were expected to be vulnerable to cement leakage by routine cementoplasty. Due to the limitation of sample size, it would be hard to conclude that eggshell method was the better treatment modality compared with the conventional BKP. However, our study suggested that eggshell method showed comparable results in severely affected MCF patients and it would help expand indications for cement injection at lower complication rates.

\section{CONFLICT OF INTEREST}

No potential conflict of interest relevant to this article was reported.

\section{REFERENCES}

1. Alberico RA: Balloon kyphoplasty for multilevel spinal metastases from breast cancer. J Support Oncol 5:243-246, 2007

2. Becker S, Tuschel A, Chavanne A, Meissner J, Ogon M: Balloon kyphoplasty for vertebra plana with or without osteonecrosis. J Orthop Surg (Hong Kong) 16:14-19, 2008

3. Berlemann U, Ferguson SJ, Nolte LP, Heini PF: Adjacent vertebral failure after vertebroplasty. A biomechanical investigation. J Bone Joint Surg Br 84:748-752, 2002

4. Cooper C, Atkinson EJ, O'Fallon WM, Melton LJ, 3rd: Incidence of clinically diagnosed vertebral fractures: a population-based study in Rochester, Minnesota, 1985-1989. J Bone Miner Res 7:221-227, 1992

5. Cosar M, Sasani M, Oktenoglu T, Kaner T, Ercelen O, Kose $\mathrm{KC}$, et al.: The major complications of transpedicular vertebroplasty. J Neurosurg Spine 11:607-613, 2009

6. Deramond H, Depriester C, Galibert P, Le Gars D: Percutaneous vertebroplasty with polymethylmethacrylate. Technique, indications, and results. Radiol Clin North Am 36:533-546, 1998
7. Do HM, Jensen ME, Marx WF, Kallmes DF: Percutaneous vertebroplasty in vertebral osteonecrosis (Kummell's spondylitis). Neurosurg Focus 7:e2, 1999

8. Dudeney S, Lieberman IH, Reinhardt MK, Hussein M: Kyphoplasty in the treatment of osteolytic vertebral compression fractures as a result of multiple myeloma. J Clin Oncol 20:23822387, 2002

9. Evans AJ, Jensen ME, Kip KE, DeNardo AJ, Lawler GJ, Negin GA, et al.: Vertebral compression fractures: pain reduction and improvement in functional mobility after percutaneous polymethylmethacrylate vertebroplasty retrospective report of 245 cases. Radiology 226:366-372, 2003

10. Feltes C, Fountas KN, Machinis T, Nikolakakos LG, Dimopoulos V, Davydov R, et al.: Immediate and early postoperative pain relief after kyphoplasty without significant restoration of vertebral body height in acute osteoporotic vertebral fractures. Neurosurg Focus 18:e5, 2005

11. Fourney DR, Schomer DF, Nader R, Chlan-Fourney J, Suki D, Ahrar K, et al.: Percutaneous vertebroplasty and kyphoplasty for painful vertebral body fractures in cancer patients. J Neurosurg 98:21-30, 2003

12. Gaitanis IN, Hadjipavlou AG, Katonis PG, Tzermiadianos MN, Pasku DS, Patwardhan AG: Balloon kyphoplasty for the treatment of pathological vertebral compressive fractures. Eur Spine J 14:250-260, 2005

13. Galibert P, Deramond H, Rosat P, Le Gars D: [Preliminary note on the treatment of vertebral angioma by percutaneous acrylic vertebroplasty]. Neurochirurgie 33:166-168, 1987

14. Garfin SR. A retrospective review of early outcomes of balloon kyphoplasty. In: North American Spine Society, ed. Annual meeting; 16th, North American Spine Society; 2001; Seattle, WA: 2001. p. 63.

15. Garfin SR, Yuan HA, Reiley MA: New technologies in spine: kyphoplasty and vertebroplasty for the treatment of painful osteoporotic compression fractures. Spine (Phila Pa 1976) 26:15111515,2001

16. Grados F, Depriester C, Cayrolle G, Hardy N, Deramond H, Fardellone P: Long-term observations of vertebral osteoporotic fractures treated by percutaneous vertebroplasty. Rheumatology (Oxford) 39:1410-1414, 2000

17. Greene DL, Isaac R, Neuwirth M, Bitan FD: The eggshell technique for prevention of cement leakage during kyphoplasty. $\mathrm{J}$ Spinal Disord Tech 20:229-232, 2007

18. Guo D, Cai J, Zhang S, Zhang L, Feng X: Treating osteoporotic vertebral compression fractures with intraosseous vacuum phenomena using high-viscosity bone cement via bilateral percutaneous vertebroplasty. Medicine (Baltimore) 96:e6549, 2017

19. Habib N, Maniatis T, Ahmed S, Kilkenny T, Alkaied H, Elsayegh $\mathrm{D}$, et al.: Cement pulmonary embolism after percutaneous vertebroplasty and kyphoplasty: an overview. Heart Lung 41:509511, 2012

20. Halpin RJ, Bendok BR, Liu JC: Minimally invasive treatments for spinal metastases: vertebroplasty, kyphoplasty, and radiofrequency ablation. J Support Oncol 2:339-351, 2004

21. Harrop JS, Prpa B, Reinhardt MK, Lieberman I: Primary and secondary osteoporosis' incidence of subsequent vertebral compression fractures after kyphoplasty. Spine (Phila Pa 1976) 29: 2120-2125, 2004 
22. Hentschel SJ, Rhines LD, Shah HN, Burton AW, Mendel E: Percutaneous vertebroplasty in vertebra plana secondary to metastasis. J Spinal Disord Tech 17:554-557, 2004

23. Hyde JA, Cohen DS, Feinberg J. Secondary osteoporotic compression fractures after kyphoplasty. In: American Academy of Orthopaedic Surgeons, ed. Presented as a poster exhibit at the Annual Meeting of the American Academy of Orthopaedic Surgeons; 2003 Feb 5-9; New Orleans, LA: 2003. p. Poster no. P31.

24. Jacobson RE, Granville M, Hatgis J, Berti A: Low volume vertebral augmentation with cortoss $(\mathrm{R})$ cement for treatment of high degree vertebral compression fractures and vertebra plana. Cureus 9:e1058, 2017

25. Jensen ME, Dion JE: Percutaneous vertebroplasty in the treatment of osteoporotic compression fractures. Neuroimaging Clin N Am 10:547-568, 2000

26. Li J, Li T, Ma Q, Li J: Using side-opening injection cannulas to prevent cement leakage in percutaneous vertebroplasty for osteoporotic vertebral compression fractures, does it really work? J Orthop Sci 22:811-815, 2017

27. Lieberman IH, Dudeney S, Reinhardt MK, Bell G: Initial outcome and efficacy of "kyphoplasty" in the treatment of painful osteoporotic vertebral compression fractures. Spine (Phila Pa 1976) 26:1631-1638, 2001

28. McCall T, Cole C, Dailey A: Vertebroplasty and kyphoplasty: a comparative review of efficacy and adverse events. Curr Rev Musculoskelet Med 1:17-23, 2008

29. McGraw JK, Lippert JA, Minkus KD, Rami PM, Davis TM, Budzik RF: Prospective evaluation of pain relief in 100 patients undergoing percutaneous vertebroplasty: results and follow-up. J Vasc Interv Radiol 13:883-886, 2002

30. McKiernan F, Faciszewski T: Intravertebral clefts in osteoporotic vertebral compression fractures. Arthritis Rheum 48:1414-
1419, 2003

31. O'Brien JP, Sims JT, Evans AJ: Vertebroplasty in patients with severe vertebral compression fractures: a technical report. AJNR Am J Neuroradiol 21:1555-1558, 2000

32. Park JH, Ju CI, Kim SW: Posterior screw fixation in previously augmented vertebrae with bone cement: Is it inapplicable? J Korean Neurosurg Soc 61:114-119, 2018

33. Pedicelli A, Lozupone E, Gatto A, Gulino P, D'Argento F, Capozzi A, et al.: Vertebra plana: reappraisal of a contraindication to percutaneous vertebroplasty. Eur J Radiol 82:2303-2308, 2013

34. Ruiz Santiago F, Santiago Chinchilla A, Guzmán Álvarez L, Pérez Abela AL, Castellano Garcia Mdel M, Pajares López M: Comparative review of vertebroplasty and kyphoplasty. World J Radiol 6:329-343, 2014

35. Semaan H, Obri T, Bazerbashi M, Paull D, Liu X, Sarrouj M, et al.: Clinical outcome and subsequent sequelae of cement extravasation after percutaneous kyphoplasty and vertebroplasty: a comparative review. Acta Radiol 59:861-868, 2018

36. Silverman SL: The clinical consequences of vertebral compression fracture. Bone 13 Suppl 2:S27-S31, 1992

37. Uppin AA, Hirsch JA, Centenera LV, Pfiefer BA, Pazianos AG, Choi IS: Occurrence of new vertebral body fracture after percutaneous vertebroplasty in patients with osteoporosis. Radiology 226:119-124, 2003

38. Wang LJ, Yang HL, Shi YX, Jiang WM, Chen L: Pulmonary cement embolism associated with percutaneous vertebroplasty or kyphoplasty: a systematic review. Orthop Surg 4:182-189, 2012

39. Zoarski GH, Snow P, Olan WJ, Stallmeyer MJ, Dick BW, Hebel JR, et al.: Percutaneous vertebroplasty for osteoporotic compression fractures: quantitative prospective evaluation of long-term outcomes. J Vasc Interv Radiol 13:139-148, 2002 